\title{
A reconfiguração das Cadeias Globais de Valor (global value chains) pós-pandemia
} AFONSO FLEURY I e MARIA TEREZA LEME FLEURY II

\section{Introdução}

$\mathrm{E}$ M TEMPOS de pandemia, o debate em torno das Cadeias Globais de Valor (CGV - equivalente a Cadeias Globais de Fornecimento e Global Value Chains) ganhou foros de estratégias nacionais e de políticas públicas. Lideradas por empresas multinacionais, as CGV podem ser definidas como processos de produção fragmentados e geograficamente dispersos que têm diferentes estágios localizados em países diferentes. As empresas multinacionais têm operações internacionais próprias, através de suas subsidiárias e, simultaneamente, criam CGV a partir de relações de fornecimento com outras empresas em diferentes países. A United Nations Conference for Trade and Development (Unctad) estima que $80 \%$ do comercio internacional envolve empresas multinacionais (WIR, 2020).

As origem e expansão das CGV estão diretamente associadas aos processos de globalização da economia num plano mais amplo, assim como ao desenvolvimento e aplicação das tecnologias digitais, que revolucionam as atividades de informação, comunicação e computação. As CGV tornaram-se redes complexas, multiníveis, que alavancam as vantagens de custos baixos, alta escala e flexibilidade espacial. Mas essa complexidade começou a cobrar seu preço: eventos não previsíveis e de maior envergadura passaram a romper os fluxos e prejudicar o desempenho. Além disso, a partir da crise financeira de 2008, com as críticas e resistências à globalização, as CGV passaram a uma posição ainda mais delicada. A conflagração da pandemia potencializou esses problemas. Na medida em que os governos nacionais e subnacionais adotavam medidas para conter a difusão do vírus, menos viável ficava a operação eficiente das CGV.

Do ponto de vista das empresas, além dos desafios colocados pelo fechamento de fronteiras, somaram-se as consequências das medidas de prevenção interna aos países, como o lockdown. Não obstante todas as empresas precisarem reinventar os seus modus operandi, os impactos da pandemia sobre as CGV foram distintos: ou elas sofreram um abrupto e significativo aumento de demanda (como foi o caso das CGV ligadas à saúde, ao entretenimento ou ao abastecimento) ou um colapso na demanda (como foi o caso do transporte aéreo, da indústria automotiva, entre outros). Do ponto de vista dos países, a ruptura 
das CGV significou o desabastecimento de bens finais e intermediários, especialmente aqueles necessários para enfrentar a crise sanitária. Isso exigiu rápidas reações dos governos para solucionar os problemas de oferta de itens essenciais e salvaguardar as empresas da insolvência para mitigar os problemas de desemprego e de instabilidade social.

Em suma, o modelo de CGV passou a ser questionado em razão de suas vulnerabilidades, dos riscos ao seu bom funcionamento, os quais podem ter várias origens: pandemias, catástrofes geológicas ou climáticas, terrorismo, convulsões políticas, entre outros. Ocorrendo um desses eventos, um dos elos da cadeia será rompido e o funcionamento das CGV será comprometido. Recentes eventos que tiveram esse efeito incluem as enchentes que ocorreram na Tailândia (2011), o tsunami no Japão (2016), a guerra comercial entre Estados Unidos e China (atual) e a atual pandemia. No plano do terrorismo comercial são cada vez mais temidos os cyberataques digitais.

Nesse cenário, há dois fatores prioritários para entender o futuro das CGV:

- do lado das multinacionais, há uma busca por CGV resilientes, capazes de operarem num contexto Vica (Volátil, Incerto, Complexo e Ambíguo, do inglês Vuca);

- do lado dos governos, especialmente os dos países desenvolvidos, há a criação de estímulos e recursos locais para que as multinacionais reduzam a sua pegada internacional, especialmente em áreas consideradas socialmente prioritárias para a soberania nacional assim como a geração de emprego e renda local.

No Brasil, esse debate tem características distintas, na medida em que as empresas multinacionais, através de suas subsidiárias, têm um papel de destaque tanto no plano tecnológico quanto no econômico desde o início do processo de industrialização. Por isso, e mais uma série de razões que serão posteriormente expostas, a participação de empresas brasileiras em CGV é relativamente modesta, o que não deixa de ser motivo de preocupação no longo prazo.

Enfim, essa complexa situação, absolutamente anômala, traz à tona não só a questão de como será a reconfiguração das cadeias globais de valor no pós-Covid, mas também como se reestruturarão os sistemas globais de produção de bens e serviços. Com esse pano de fundo, o objetivo deste artigo é revelar os fatores determinantes da gênese e evolução das CGV, culminando com a pandemia, para então esboçar algumas tendências do que pode vir a ser o futuro das CGV. Evidentemente essa análise tem sempre o caso do Brasil como prioridade, embora isso dependa do papel que o país vem se comportando nesse fenômeno.

\section{Os conceitos e tipologias para a análise das CGV}

O estudo das CGV envolve os seguintes atores: as empresas multinacionais, principalmente aquelas dos países desenvolvidos, que geralmente lideram as CGV, outras empresas articuladas nas redes e cadeias de produção, os go- 
vernos nacionais nas suas diferentes instâncias e as instituições que regulam o comércio internacional.

Em meados da década de 1990, começaram a surgir os primeiros estudos sobre CGV, que foram definidas como a transformação de insumos em bens e serviços no qual os diferentes estágios desse processo estão localizados em diferentes países. Mais tarde, em artigo seminal, Gereffi, Humphrey e Sturgeon (2005) observaram que, através das CGV, as multinacionais orquestram a coevolução da organização industrial entre fronteiras de países.

Esses autores identificaram duas características especificas de CGV: Governance e Upgrading. O termo governance se refere ao fato de que algumas firmas na cadeia estabelecem e/ou impõem os parâmetros para o seu funcionamento (Humphrey; Schmitz, 2001). Dois padrões de governance foram identificados. Nas cadeias Comandadas pelo Produtor (Producer-Driven), a governance seria exercida por empresas de manufatura, com base em sua superioridade tecnológica. Um exemplo é a indústria automotiva na qual Volkswagen ou Ford seriam líderes. Já nas cadeias Comandadas pelo Comprador (Buyer-Driven), a governance estaria com empresas de comercialização, que exerceriam esse poder em razão da força de suas marcas, da sua rede de distribuição e do acesso ao cliente final. Exemplos seriam as grandes marcas de vestuário, como GAP e Nike, ou de alimentação, como Carrefour, Tesco e Walmart. Evidentemente, a questão da governança está diretamente associada a poder e, consequentemente, à distribuição de margens entre as empresas que compõem a cadeia de valor. Um caso ilustrativo é aquele protagonizado pela Apple e a cadeia de produção do IPhone: a margem de lucro por aparelho da Apple estaria em torno de $40 \%$, enquanto a da Foxconn, a empresa chinesa que faz a montagem, é de menos que 1\%.

Já o upgrading está associado a uma noção de mobilidade na cadeia de valor. Uma empresa pode estar numa determinada posição da cadeia mas passar para uma outra, de maior autonomia em relação ao líder ou de maior captura de margem, a partir do aumento de suas capacitações. Em princípio se cogitou de uma certa hierarquia, na qual as empresas com menor status na cadeia seriam aquelas capacitadas para fazerem a produção (denominadas OEM - Original Equipment Manufacturers). Se essas empresas aumentassem sua capacitação no desenvolvimento de produtos e serviços poderiam fazer o upgrading para ODM (Original Design Manufacturers) e, se evoluíssem ainda mais, poderiam passar a OBM (Original Brand Manufacturers). Inúmeras empresas percorreram essa trajetória, alguns casos mais conhecidos sendo as coreanas (Samsung e Hyundai), chinesas (Lenovo e Haier) e brasileiras (Embraer e Natura).

Por outro lado, a hierarquia acima proposta serviu para revelar um novo conjunto de empresas que surgiam no contexto da globalização. Um deles foi o dos "contractors", empresas que passaram a fazer um papel de intermediação nas cadeias comandadas pelo comprador e de especialização nas cadeias comandadas pelo produtor. Por exemplo, na cadeia de Telecomunicações, Informáti- 
ca e Computação (TIC), surgiram os "manufacturing contractors", empresas como a Flextronics e a Solectron, que se especializaram na fabricação de componentes e montagem de sistemas para praticamente todas as multinacionais dessa indústria. Ou seja, elas se concentraram no OEM e desenvolveram uma pegada global; a Flextronics está instalada no Brasil desde 1996, quando as empresas de telecomunicações aqui instaladas (Ericsson, NEC, Alcatel, entre outras) praticamente encerraram as suas atividades de produção, passando a subcontratar com a Flextronics.

Nas cadeias comandadas pelo comprador, o conceito de "service contractor" faz referência a um intermediário que organiza diferentes cadeias de fornecimento dependendo das demandas especificadas por uma empresa líder. Por exemplo, na cadeia de vestuário, uma empresa que tem a marca e a distribuição desenha uma nova coleção contrata um "apparel contractor” que vai se responsabilizar por todo o processo de produção, conforme especificações. Esse intermediário monta uma cadeia de fornecimento conforme sua conveniência. $\mathrm{Na}$ indústria de vestuário, empresas coreanas, depois de aprenderem fazendo a produção como OEM, passaram a dominar a intermediação em grande escala, sendo subcontratadas pelas grandes marcas globais e subcontratando em todo o mundo, inclusive na África.

Em outras palavras, com a globalização e a formação das CGV, a tipologia de empresas que participa dos sistemas globais de produção se diversificou, passando a incluir perfis bastante distintos. Mas, para justificar essa diversificação, devemos explicitar mais detalhadamente a dinâmica da formação das CGV, lideradas pelas multinacionais.

\section{As multinacionais e as CGV}

Há, na literatura, um certo consenso de que a aceleração da globalização se deu a partir da década de 1970 em três impulsos distintos (Baumann, 1996). O primeiro quando os avanços na computação digital e a liberalização dos fluxos de capitais entre países resultou no início da globalização financeira (as moedas passaram a circular globalmente). O segundo, na década de 1980, quando as mercadorias passaram a circular com maior facilidade, a chamada globalização comercial. Nesse período, as políticas de comércio internacional passaram de protecionistas a liberais, com drásticas reduções nas alíquotas de importação, as quais, associadas ao desenvolvimento de sistemas de informação com a introdução da microeletrônica e à introdução dos containers no transporte marítimo, possibilitaram a eficiente movimentação de bens e suas partes. Finalmente, o terceiro movimento foi denominado globalização produtiva.

Na década de 1990, as empresas multinacionais passaram a se reestruturar. Com a incorporação das chamadas TIC e aproveitando das condições criadas pela globalização financeira e comercial, elas focaram suas estratégias em atividades de maior potencial de inovação e maior agregação de valor, racionalizaram suas estruturas organizacionais e subcontrataram as atividades rotineiras, aquelas 
que agregam menos valor. Ou seja, essas empresas redefiniram suas cadeias de valor a montante (atividades relacionadas à obtenção de insumos) e a jusante (atividades relacionadas a clientes e mercados).

Nesse processo, as multinacionais racionalizaram as suas redes internacionais próprias, as redes de subsidiárias, eliminando algumas e mudando o papel desempenhado por outras. Até aquele momento, as subsidiárias operavam dentro de um padrão relativamente autônomo, suas estruturas organizacionais replicavam as das matrizes, sendo descritas como multidomésticas. A partir dessa época, o papel que cada subsidiária desempenharia para o atingimento das metas globais da corporação, e consequentemente a sua estrutura organizacional, passou a ser analisado em conjunto. Passou a haver coordenação, integração e competição entre subsidiárias. O papel de cada subsidiária foi definido em razão da importância do mercado atendido e do nível de suas capacitações internas. O resultado foi, por exemplo, a especialização de subsidiárias em determinados componentes ou produtos, a racionalização de atividades de Pesquisa e Desenvolvimento no plano global, com o fechamento de departamentos de P\&D em países que passaram a realizar apenas atividades de produção.

A postura das multinacionais dos países desenvolvidos de focar em atividades intensivas em inovação e altamente agregadoras de valor tinham repercussão e apoio no plano governamental. A manifestação mais clara nesse sentido foi de Robert Reich, então secretário do Trabalho na primeira gestão Clinton, a partir do seguinte argumento. Há três tipos de trabalho: o trabalho rotineiro de produção, o trabalho rotineiro de serviços e o trabalho mental, qualificado e qualificante. Esse último é o que interessa aos Estados Unidos e tem que ser incentivado; o segundo não interessa tanto, mas não pode ser exportado; o primeiro não tem interesse e tem que ser exportado. Criou-se, assim, uma dinâmica macro-micro com feedback positivo que acelerou o processo de reestruturação das multinacionais. Aos processos de subcontratação (outsourcing) juntaram-se os processos de offshoring, que não se restringiram à produção apenas, mas envolveram também compras e logística, gestão de informações e analytics, gestão de recursos humanos, gestão financeira, engenharia e atendimento ao cliente.

Nesse contexto, surgem no radar das multinacionais os países emergentes com excelentes perspectivas de desenvolvimento e crescimento. As redes internacionais das multinacionais se amplificam nos países emergentes, seja por crescimento orgânico (unidades greenfield), seja por aquisições, seja por subcontratações. Ou seja, as multinacionais ou descentralizam as suas operações pela ampliação de sua rede de subsidiárias e/ou criam redes de fornecedores nos países emergentes. O potencial de crescimento dos países emergentes, num momento em que os mercados dos países desenvolvidos eram estacionários, foi uma motivação extra para a reorganização das atividades das multinacionais. As condições eram tão favoráveis que algumas tradicionais multinacionais chegaram a cogitar mudar o seu headquarter para algum desses países. Mas a dinâmica 
expansionista das multinacionais e das CGV criou seus próprios problemas, passa a encontrar dificuldades, e precisa ser redefinida, como veremos.

Enquanto isso, os países emergentes não jogaram papel passivo, especialmente a China que negociou os espaços de atuação das multinacionais estrangeiras dentro de um minucioso processo de capacitação tecnológica das empresas locais. A partir de 2000, multinacionais dos países emergentes começam a se destacar no cenário internacional. Lenovo, Haier, Huawei, Embraer, WEG, Iochpe-Maxxion, entre outras, avançam nas CGV criadas pelas incumbentes principalmente através de aquisições (Fleury; Fleury; Borini, 2013). Algumas alcançam a posição de líderes de CGV.

\section{Os países se reposicionam frente às $\mathrm{CGV}$}

Na dinâmica da globalização dos anos 1990, a importância atribuída às multinacionais foi enorme. John Dunning, um dos pioneiros dos estudos de Negócios Internacionais, declarava que "the key ingredients of contemporary economic growth - created assets, such as technology, intellectual capital, learning experience and organisational competence - are not only becoming more mobile across national boundaries, but they are increasingly housed in TNCs - Transnational Corporations - systems; governments are eager to have more of them" (Dunning, 1994, p.26). Ou seja, por seu papel estratégico no desenvolvimento, as multinacionais eram disputadas não só pelos países emergentes, mas também pelos próprios países desenvolvidos.

Os atrativos oferecidos eram não só de base financeira (redução de impostos, subsídios para implantação de greenfields...) como infraestruturais (desenvolvimento de distritos industriais com todas as facilidades state-of-the-art, especialmente de comunicação e de logística) e disponibilização de cadeias de fornecimento local para insumos necessários, entre outros. Os países asiáticos como Singapura e Malásia, talvez mais que a China, por terem mercados pequenos, usaram intensamente essas políticas. O Brasil adotou esse posicionamento especialmente no governo Itamar Franco e um dos objetivos prioritários era atrair novas empresas automobilísticas. Nessa época iniciaram operações: Renault, Peugeot, Honda, Mercedes Benz (carros) e BMW, entre outros.

Evidentemente, as multinacionais jogavam o jogo nessa competição entre países, e aumentavam a sua presença internacional. A formação das CGV estava totalmente coadunada com essa perspectiva. A forte expansão das CGV permitiu às multinacionais eficiência de custos, flexibilidade de produção com escala, focalização nas atividades de maior agregação de valor para a inovação radical. Entre 2000 e 2010, o valor de bens intermediários comercializados globalmente triplicou, chegando a mais de US\$ 10 trilhões por ano.

As primeiras contestações a essa expansão apareceram no contexto da crise financeira global de 2007-2009, a qual acentuou a polêmica dos ganhadores e perdedores com a globalização. De maneira geral, as questões sociais, especialmente o desemprego tecnológico, a desigualdade e as migrações, forneceram ar- 
gumentos para a contestação da globalização e consequentemente das atividades comandadas pelas multinacionais.

Nos seus países de origem as multinacionais eram culpabilizadas por problemas de desemprego, especialmente no setor de manufatura, e enfrentavam acusações quanto a questões de sustentabilidade. Para os governos, a questão-chave passou a ser emprego e renda e o desafio passou a ser o de definir novas bases para a recriação dos sistemas de produção. Para tanto, começaram a incentivar o desenvolvimento e a adoção das tecnologias digitais na medida em que elas poderiam dar conta das atividades rotineiras de produção: a robótica, a impressão 3D, a Internet-das-Coisas seriam recursos para produzir de maneira eficiente e flexível, sem necessidade de fragmentar a produção e buscar outras localidades. As tecnologias digitais possibilitariam a manufatura distribuída na qual a produção seria feita próxima ao consumidor, em pequenas fábricas com cadeias de fornecimento curtas, entregando produtos e serviços customizados a um custo ambiental menor. A digitalização promoveria também a "economia circular" através do smart design, pela colaboração nas cadeias de fornecimento em termos de compartilhamento de dados, o monitoramento do uso para prolongar a vida dos produtos e promover o reúso. Começando em 2007, os governos dos países desenvolvidos passaram a promulgar programas de estimulo a indústria digital tendo em vista criar as condições para o desenvolvimento e implantação desse novo modelo de produção e consumo: Estados Unidos (Manufacturing in America - 2007), Alemanha (Industrie 4.0 - 2011), Japão (Society 5.0) e China (Made in China -2025), entre outros

Nos países emergentes (exceto China), as questões sociais, especialmente o desemprego, a desigualdade e os conflitos, passaram a favorecer os governos populistas e forneceram argumentos para o ressurgimento do nacionalismo tecnológico e a contestação das atividades comandadas pelas multinacionais.

\section{As CGV se tornam complexas e precisam criar resiliência}

A expansão e a complexificação das CGV carregavam problemas e disfuncionalidades que aos poucos foram emergindo. Do ponto de vista do contexto das operações globais, desastres naturais e climáticos, associados às consequências de conflitos políticos nacionais e regionais, criavam vulnerabilidades e prejudicavam significativamente o desempenho das cadeias. Do ponto de vista interno às operações, surgiram problemas associados à perda da vantagem tecnológica na medida em que esse conhecimento era transferido a outras empresas, de maneira formal e explícita ou mesmo informal. $\mathrm{O}$ distanciamento das atividades de produção das demais atividades do ciclo de desenvolvimento de produtos e serviços reduziu a competitividade e eventualmente criou competidores.

Algumas CGV, incluindo têxteis e equipamento de comunicação e computação, ampliaram a dispersão geográfica entre duas e três vezes. Em torno de $80 \%$ do comércio mundial passou a fluir através de países com conflitos políticos e a produção a ocorrer em países sujeitos a desastres naturais e climáticos. Estu- 
dos da McKinsey ratificam que as empresas já estavam enfrentando dificuldades com as CGV muito antes da pandemia; foi estimado que paralizações durando mais do que um mês ocorriam em média a cada 3,7 anos e que, em algumas indústrias, esses eventos inesperados, chegavam a custar a maior parte dos lucros acumulados em uma década (McKinsey, 2020). Algumas dessas vulnerabilidades são função do tipo de indústria. Alimentos e produtos agrícolas tem problemas de perecibilidade que outras indústrias não têm. As indústrias cuja demanda é cíclica ou sazonal têm problemas distintos, não podendo deixar de atender os picos de vendas como a época natalina ou o Black Friday.

Nesse contexto, emergiu o conceito de resiliência, definido como a capacidade de uma empresa de enfrentar as consequências de eventos inevitáveis de maneira a recuperar as condições originais ou evoluir para um novo e mais desejável patamar depois do distúrbio (Ponomarov; Holcomb, 2009). No plano operacional, várias medidas passaram a ser implantadas para aumentar a resiliência como: criar estoques para mitigar o risco de falta, subcontratar capacidades adicionais, criar redundâncias no suprimento e na infraestrutura logística, implantar sistemas de distribuição multicanais (ominichannel), tornar os sistemas de produção mais ágeis e flexíveis com decisões baseadas em dados (data-driven) e monitorar, em tempo real, toda a cadeia de valor. O desenvolvimento, a implantação e a operação dessas três últimas medidas foram alavancados pelas tecnologias digitais que têm o potencial de monitorar vários níveis de fornecedores, acelerar os tempos de resposta e simular cenários alternativos. Não obstante, a digitalização aumenta o risco de cyber ataques, o que está levando as empresas a investirem pesadamente em segurança de redes.

Mais importante ainda, no plano das empresas houve a necessidade de mudanças na cultura organizacional. Os princípios tradicionais de eficiência e eficácia precisaram ser redefinidos, numa condição em que a existência de fatores externos imprevisíveis e inevitáveis passaram a ter que fazer parte do cotidiano das empresas. Aos poucos, a questão da resiliência das cadeias de valor passou do plano tático-operacional para o plano estratégico das empresas.

\section{O Brasil nas CGV}

A participação do Brasil nos sistemas internacionais de produção é relativamente importante sob o ponto de vista das redes internas das multinacionais (subsidiarias) e relativamente modesta sob o ponto de vista das suas redes externas, as CGV.

É certo que, desde há muito tempo, o Brasil tem posição relevante em cadeias de fornecimento de commodities (minério de ferro, soja, açúcar, café etc.) mas essa posição a montante nem sempre significa posição forte na governance das cadeias de valor. Por outro lado, o processo de industrialização do Brasil foi dependente de multinacionais estrangeiras, que intensificaram sua presença no país, principalmente a partir da década de 1950 , com a instalação de subsidiárias próprias. Através delas, as multinacionais lideraram o desenvolvimento 
das indústrias intensivas em tecnologia (automotiva, linha branca, máquinas-ferramenta etc.) enquanto as empresas brasileiras se posicionavam em setores de menor intensidade tecnológica (alimentos, bebidas, vestuário etc.). As posições nas cadeias de fornecimento locais foram muitas vezes ocupadas por subsidiárias de outras multinacionais, mas também deram ensejo ao surgimento de empresas locais competitivas em segmentos intensivos em tecnologia. É o caso de Metal Leve e Cofap na cadeia automotiva, da Embraco na cadeia de linha branca, da Romi na indústria de máquinas e ferramentas, entre outras. Havia um pressuposto de que as multinacionais gerariam um efeito spillover (transbordamento) que facilitaria o upgrade das empresas brasileiras no contexto internacional, o que ocorreu em parte.

Consistentemente com o quadro acima, quando as CGV começaram a ser configuradas, na década de 1980, os setores convidados foram calçados e vestuário, já que o suprimento nos setores mais intensivos em tecnologia já estava aqui estabelecido. As empresas brasileiras foram sondadas para participar de buyer-driven chains, lideradas por multinacionais de marca e distribuição que estavam interessadas em que as empresas locais assumissem operações de produção. As empresas estrangeiras enviariam as especificações do produto e as empresas locais fabricariam os itens de acordo com o especificado (OEM). Ao mesmo tempo que as multinacionais compradoras não estavam interessadas nas capacidades de design ou de marketing das empresas nacionais, as encomendas seriam em escala muito maior do que aquelas já instaladas, o que implicaria significativos investimentos em capacidade de produção. O trade-off implicaria priorizar o fornecimento internacional como um ator da CGV em detrimento dos mercados locais; ficava em aberto a possibilidade do upgrading. A grande maioria das empresas nacionais não aceitou. $\mathrm{O}$ caso que melhor se configurou a esse contexto foi a cooperativa de calçados que se formou em Novo Hamburgo, Rio Grande do Sul, para fornecer para redes internacionais de calçados.

Nesse ponto, uma comparação com a Coreia é ilustrativa. A Coreia iniciou seu processo de internacionalização bem mais tarde que o Brasil, de modo que na época em que as CGV estavam sendo formadas, esse país estava no início da transição de uma economia agrícola para uma economia industrial. Aproveitando o momento, a indústria coreana teve forte inserção nas CGV. Há casos reportados de fábricas com 11 mil pessoas costurando material esportivo. A partir de então as empresas coreanas investiram no upgrading e o país realizou um processo de catching-up tecnológico e econômico, liderado pelo governo e os grupos empresariais locais (os Chaebol) que a levou a atingir o status de país desenvolvido em 1996, quando foi admitida na OECD.

Voltando ao caso do Brasil, no início da década de 1990, o governo Collor criou políticas para reverter a estratégia de substituição de importações que caracterizou a industrialização brasileira e aumentar a competitividade com a abertura dos mercados brasileiros ao comércio internacional. Houve um extenso 
processo de modernização produtiva pautado principalmente pelo Programa Nacional para a Qualidade e Produtividade. Várias empresas nacionais atingiram os padrões de excelência operacional necessários para operar nos mercados internacionais, tornando-se multinacionais brasileiras (Fleury; Fleury, 2011), algumas das quais articuladas em CGV, havendo casos excepcionais como o da Embraer, que se tornou líder de CGV. Muitas vezes, o avanço das empresas brasileiras nas CGV se dava em razão de vazios criados pelas reestruturações das multinacionais líderes que, para concentrar seus recursos em atividades inovadoras e com maior agregação de valor, se desfaziam das operações mais tradicionais. Multinacionais brasileiras chegaram a ser consideradas consolidadores globais (Ramamurti; Singh, 2008), como foi o caso da Braskem em polipropileno e da WEG em motores elétricos.

Ao mesmo tempo, a turbulência político-econômica da época, com a inflação atingindo níveis astronômicos, trouxe problemas insuperáveis a várias empresas (incluindo algumas líderes como Metal Leve e Cofap), o que resultou num processo de desnacionalização da indústria brasileira. Houve um significativo avanço das multinacionais estrangeiras através de subsidiárias próprias, especialmente em segmentos novos como o setor de TIC e mesmo em setores já estabelecidos como o de autopeças.

Após a estabilização conseguida com o Plano Real, as políticas econômica e industrial passaram a ser pautadas pelo Consenso de Washington, que priorizava o mercado em detrimento de ações mais estruturadas para o desenvolvimento industrial local, o que, mais uma vez, favoreceu as multinacionais estrangeiras. O governo Lula fez tentativas de relançar políticas industriais que, não obstante, não foram bem-sucedidas. O polêmico apoio às "campeãs nacionais" selecionou empresas com baixa capacidade de fomentar inovações ou mesmo de criar as suas próprias CGV.

Além da questão de fundo de que produzir no Brasil é mais caro do que produzir em inúmeros outros países e regiões devido ao Custo Brasil, como atestam estudos da Confederação Nacional da Indústria e do Instituto para o Desenvolvimento Industrial (Iedi), as limitações à participação de empresas brasileiras em CGV têm origem também no plano das relações diplomáticas e dos acordos comerciais. O único acordo comercial que o Brasil continua signatário é o Mercosul, com os seus conhecidos conflitos e limitações. A Área de Livre Comércio das Américas (Alca) foi abandonada em 2006, o acordo com a União Europeia continua emperrado e, de certa forma, o Brasil deixou de ficar em situação ainda mais periférica no momento em que o Acordo Transpacífico, criado na gestão Obama, foi descontinuado na gestão Trump. Esse acordo favoreceria a posição dos países latino-americanos que olham o Pacífico, em detrimento dos que olham o Atlântico.

Dados todos esses condicionantes, fica a questão: como realmente fica a posição do Brasil nas CGV? No seu relatório World Investment Report de 2013, 
a Unctad fez um esforço no sentido de medir como as CGV influenciavam o comercio internacional. A partir da base de dados organizada para esse fim (Unctad-Eora database) foi criado um conjunto de indicadores que incluíam o valor adicionado importado (o valor adicionado por outros países nas importações do pais), o valor adicionado doméstico (o valor adicionado localmente nas exportações), e o valor adicionado doméstico embutido nas exportações de outros países. A Tabela 1 apresenta um dos resultados desse exercício para destacar a participação do Brasil.

Tabela l - Resultados de exercício de participação do Brasil

\begin{tabular}{l|l|l|l}
\hline \multicolumn{1}{c|}{$\begin{array}{c}\text { Valor adicionado domesticamente } \\
\text { no valor das exportações }\end{array}$} & \multicolumn{2}{c}{$\begin{array}{c}\text { Taxa de participação em CGV } \\
\text { (valor transacionado através de CGV) }\end{array}$} \\
\hline Rússia & $91 \%$ & Singapura & $82 \%$ \\
\hline Índia & $90 \%$ & Malásia & $68 \%$ \\
\hline Estados Unidos & $89 \%$ & Coreia & $63 \%$ \\
\hline Brasil & $87 \%$ & China & $59 \%$ \\
\hline Austrália & $87 \%$ & Rússia & $56 \%$ \\
\hline China & $70 \%$ & México & $44 \%$ \\
\hline México & $68 \%$ & Austrália & $42 \%$ \\
\hline Malásia & $58 \%$ & Brasil & $37 \%$ \\
\hline Coreia & $56 \%$ & Índia & $36 \%$ \\
\hline
\end{tabular}

Fonte: Unctad -Eora CGV Database.

Este exercício só foi feito na data acima. Ele é relevante para nossa análise porque a partir da crise financeira de 2008 as CGV começam a encolher. Essa tabela revela, então, o ponto de máxima integração das CGV.

A coluna "valor adicionado domesticamente no valor das exportações" dá uma ideia do grau de fechamento e autossuficiência dos países que, combinado com a taxa de participação, resulta numa melhor noção do grau de envolvimento em CGV. Por exemplo, Coreia e Malásia recebem produtos que já tem valor adicionado por outros países ( $44 \%$ e $42 \%$ respectivamente) e tem significativa participação em CGV, enquanto Brasil e Índia processam prioritariamente insumos locais e têm participação em CGV relativamente baixa.

Esse quadro foi pouco alterado durante esta última década, mas para o Brasil os números indicam retração. De acordo com recente relatório da United Nations Industrial Development Organization (Unido, 2020), a fatia do Brasil no valor adicionado da indústria mundial, após ter alcançado $2 \%$ em 2010 , encolheu para $1,24 \%$ em 2018 e $1,19 \%$ em 2019 . O país caiu para a $16^{a}$ posição no ranking das potencias industriais atrás de países emergentes como China $\left(1^{\mathrm{a}}\right)$, Índia $\left(5^{\mathrm{a}}\right)$, Coreia $\left(6^{\mathrm{a}}\right)$, Indonésia $\left(10^{\mathrm{a}}\right)$, México $\left(11^{\mathrm{a}}\right)$ e Turquia $\left(15^{\mathrm{a}}\right) \mathrm{Na}$ 
avaliação do Instituto de Estudos de Desenvolvimento Industrial (Iedi) deve ser mantida a tendência de queda da participação na transformação mundial.

Por outro lado, o Investimento Estrangeiro Direto, que é um indicador das atividades das multinacionais no país, depois de um pico em 2010 (quase US\$ 25 bilhões) e de um vale em 2013 (US\$ 13 bilhões) vem se recuperando gradualmente e em 2019 voltou ao nível de 2010. O recente relatório do Global Innovation Index (WIPO, 2020) revelou uma pequena melhora do índice do Brasil, mas que permanece na $62^{\text {a }}$ posição. Parte dessa melhora é atribuída a novas implantações de multinacionais que realizam Pesquisa e Desenvolvimento. Ou seja, as atividades ligadas às multinacionais estrangeiras, se não se expandiram estão se mantendo

\section{A pandemia coloca as CGV em xeque}

A pandemia do Covid-19, aliada à ascensão do nacionalismo econômico em certos países (por exemplo, o America First nos Estados Unidos) evidenciaram os problemas decorrentes da produção em redes de suprimento muito complexas. Os fluxos entre países foram prejudicados e a necessidade de produção local passou a ter uma relevância muito maior. A noção de que o elo frágil da cadeia poderia interromper temporária ou permanentemente o funcionamento de toda a rede ganhou proeminência. Para algumas CGV a demanda cresceu drasticamente e a oferta não conseguiu atender de maneira satisfatória (exemplo: respiradores), colocando em risco a sobrevivência das populações. Outras CGV tiveram a demanda subitamente estancada resultando em paradas de produção, perigo de insolvência e necessidade de suporte governamental (exemplo: transporte aéreo, automotiva, entre outras).

De acordo com Gereffi (2020), antes da crise pandêmica havia uma interdependência de comércio e produção de produtos médicos na qual países avançados, especialmente Estados Unidos, Suíça, Holanda, Alemanha e Reino Unido, se especializavam em produtos sofisticados de alta tecnologia, enquanto países com baixo custo de produção, especialmente China e Malásia, forneciam peças e componentes, assim como lideravam a produção de aparelhos mais simples (Equipamentos de Proteção Individual). Por sua vez, as multinacionais que lideram as CGV têm subsidiárias em várias partes do mundo especialmente nos novos polos de manufatura da China, Coreia e México, assim como plantas mais focadas em inovação localizadas em países menores como Irlanda, Nova Zelândia, Costa Rica e Singapura. Não obstante seja uma referência em pesquisas, o Brasil não participa diretamente das CGV ligadas à saúde. Quando a pandemia foi conflagrada, as reações aos diferentes tipos de demanda foi como se segue.

No quesito máscaras, no primeiro momento de desconhecimento e pânico e da necessidade de proteger os médicos e enfermeiras, surgiu um mercado especulativo que vendia máscaras importadas por cerca de dez vezes o seu valor original. Aos poucos, com as fábricas chinesas aumentando significativamente a 
sua produção, esses valores foram normalizando. Na medida em que a indústria têxtil local tem grande capacidade e capacitação, foram sendo atendidas as demandas das outras parcelas da população.

No quesito respiradores, já havia uma empresa produtora brasileira, mas sua capacidade produtiva não atendia, em absoluto, o volume demandado. Assim, houve uma primeira corrida para comprar respiradores da China comandada por diferentes atores, governo federal e governos estaduais principalmente. Nem sempre o processo de compra seguiu os tramites legais, tendo havido várias denúncias de desvio e compras de fornecedores inidôneos. A essas encomendas somaram-se os esforços de empresas e instituições locais que desenvolveram novos projetos, como foram os casos da WEG, multinacional brasileira líder global em sistemas de energia, e do respirador de baixo custo desenvolvido pela Escola Politécnica da USP, entre muitos outros. Quanto aos testes, a questão é mais opaca. Sabe-se que o governo federal comprou um grande lote ( 12 milhões) na China, sendo auxiliada pela Vale, multinacional no setor de mineração. Esses testes não chegaram a ser aplicados por falta de algum insumo básico. Por outro lado, algumas instituições locais começaram a desenvolver e produzir testes, como foi o caso do Instituto Butantan.

Finalmente, no quesito vacina, o Brasil passou a fazer parte de CGV na medida em que o Brasil foi escolhido para o teste de vacinas e instituições como Fiocruz e Instituto Butantan passaram a interagir nas estruturas criadas por AstraZeneca - Universidade de Oxford e Sinovac, respectivamente.

\section{Comentários finais:}

\section{quais são as perspectivas para as CGV no pós-Covid?}

Com os limites da expansão já tendo sido atingidos e os fatores disruptivos já identificados, as CGV estavam sendo gradualmente reformuladas dentro de uma abordagem de resiliência. Mas as crises políticas e econômicas, que já estavam em curso e foram brutalmente aceleradas pelo Covid-19, estão provocando impactos significativos na dinâmica do comércio internacional e dos sistemas globais de produção. Baseados nos argumentos previamente apresentados, os cenários sobre o futuro das CGV vão ser definidos pelas multinacionais líderes, sob novos critérios de resiliência técnica, econômica e geopolítica, sob novas lógicas de pressão e regulação dos governos, num contexto de abruptas e imprevisíveis mudanças nos sistemas de governança global.

Mesmo sob condições disruptivas, desfazer e refazer um tecido de relações de complementaridade que foi organizado em quatro décadas não é um projeto de curto prazo. A WTO prevê uma queda no comercio mundial entre $13 \%$ e $32 \%$, enquanto a Unctad prevê uma contração no FDI de 30\% a 40\% entre 2020 e 2021 (Unctad, 2020). Isso sinaliza as reações de curto prazo, para mitigar os problemas emergenciais. Não só as empresas estão se adaptando às imposições do combate a pandemia, como também estão redimensionando e racionalizando suas atividades locais e internacionais, para então passar a um processo de 
reestruturação visando novos modelos de negócio, com novas configurações internacionais.

Apesar da pressão dos governos locais, a manutenção das operações internacionais se justifica em termos de mercados (a receita nos mercados externos é extremamente significativa), inovação (a diversidade cultural e social dos mercados é ingrediente fundamental) e escala (para amortizar investimentos). Do ponto de vista da rede externa ( $\mathrm{CGV})$, pode-se aventar que haverá uma tendência de desconcentrar as operações internacionais para não ficar dependente de nós frágeis, o que significa aumentar o número de países ou regiões de operação, dentro de critérios de escolha que priorizam a estabilidade e transparência político-institucional. Do ponto de vista da rede interna (subsidiárias), prevê-se maior intensidade de operações regionais e significativos investimentos em tecnologias digitais para aumentar a resiliência com respeito a riscos externos e responder a demandas locais, de governos e clientes.

Ao mesmo tempo, é necessário relembrar que as diferentes indústrias enfrentam desafios, dependendo de suas características intrínsecas. As mais afetadas pela pandemia foram as de viagens, turismo e aeronáutica; as previsões para o início de recuperação são para o início de 2022, e as empresas aéreas estimam chegar ao patamar pré-Covid em 2024/2025 com 80\% da frota atual. Como os produtores de aeronaves e seus fornecedores vão enfrentar essa situação é um extraordinário desafio. Enquanto isso, CGV associadas a indústrias como saúde, fármacos, telecomunicações e tecnologia estão em pleno processo de expansão para atender demanda reprimida.

Quanto aos governos dos países desenvolvidos, a tendência é influenciarem e mesmo intervirem cada vez mais nas decisões das empresas para enfrentar desafios de soberania e segurança nacionais, como emprego e renda. Nesse sentido, um dos subprodutos da pandemia foi o despertar das empresas para questões de Responsabilidade Social Corporativa que, de alguma forma, cria um link com o enfrentamento dos problemas sociais.

Além disso, há duas novas incógnitas: as bigtechs e a China. Como empresas-plataforma, Amazon, Apple, Google, Facebook, Microsoft, entre outras, já comandam impressionante número de cadeias de valor, especialmente nas chamadas indústrias digitais (informática, entretenimento, relações sociais...) e de serviços (Facebook e Apple no setor financeiro). Mas, na medida em que elas coordenam as transações entre empresas e entre empresas-clientes, há a possibilidade de que elas se interessem em dominar segmentos de maior agregação de valor em cadeias que elas ainda não exploraram. Quanto à China, o ritmo de sua evolução tecnológica, em diferentes indústrias, vem surpreendendo o mundo. Recentes notícias veiculadas na mídia já colocam a China como competidora da Alemanha em equipamentos industriais, fato reconhecido pelos próprios empresários alemães (Valor, 21.9.2020, p.A16). Como as empresas chinesas vão influir na reconfiguração das CGV ainda está em aberto. 
No plano das relações internacionais e da governança global, está cada vez mais evidente que os conflitos internacionais poderão ser de longo prazo, transformando um contexto no qual havia uma certa cooperação em um outro caracterizado por antagonismo e competição, o que inclui o desmonte do sistema de regulação do comércio internacional como a WTO sob iniciativa dos Estados Unidos. Da mesma forma, os analistas admitem que mesmo com uma mudança na presidência dos Estados Unidos, o contencioso com a China pode se acirrar ainda mais. O governo Trump desde seu início exerceu pressão sobre as multinacionais para repatriar operações e empregos, afetando o modo como elas organizavam as suas CGV. Do lado chinês, o governo já está praticando políticas para reduzir a vulnerabilidade do país às vicissitudes das CGV. Segundo The Economist (15.8.2020, Briefing) ao invés de políticas industriais de largo espectro como a "Made in China 2025", o presidente Xi está mudando o foco para os nós das cadeias de suprimento nos quais a China é frágil, o que inclui criar autossuficiência em tecnologias chave como semicondutores e baterias. Recorde-se que hoje a empresa líder global em semicondutores é a Taiwan Semiconductors Manufacturing Company (TSMC), que superou a Intel dos Estados Unidos nas últimas gerações de chips.

No caso do Brasil, há campo para o aumento de participação em CGV através da internacionalização de empresas no setor de agronegócios e alguns nichos de serviços, aproveitando a onda da digitalização. As atuais multinacionais brasileiras podem aumentar sua presença em suas respectivas CGV. Importa também criar CGV em áreas nas quais o país tem vantagens comparativas como a bioeconomia, economia verde ou economia de baixo carbono. O país já tem relevância nesse campo e há estudos detalhados sobre como avançar desde que haja vontade política e as políticas habilitadoras. No caso das multinacionais estrangeiras no Brasil, há possibilidade de elas virem a reconfigurar suas redes de subsidiárias no país, mas não está claro se isso vai em direção ao empoderamento e autonomia, ou vice-versa.

Para finalizar, só nos resta ratificar que o futuro é incerto. O melhor modo de lidar com uma situação como essa é conhecer os fatores intervenientes, monitorá-los sistematicamente e estar preparados para reagir. Neste artigo esperamos ter proporcionado alguns insights sobre como abordar o fenômeno das CGV.

\section{Referências}

BAUMANN, R. O Brasil e a economia global. Rio de Janeiro: Editora Campus, 1996.

DUNNING, J. H. Re-evaluating the benefits of foreign direct investment. Transnational Corporations, v.3, n.1, p.23-51, 1994.

FLEURY, A.; FLEURY, M. T. Brazilian multinationals: competences for internationalization. Cambridge - UK: Cambridge University Press, 2011. 
FLEURY, A.; FLEURY, M. T.; BORINI, F. The Brazilian multinationals' approaches to innovation. Journal of International Management, v.19, p.260-75, 2013.

GEREFFI, G. What does the Covid-19 pandemic teach us about global value chains? The case of medical supplies. Journal of International Business Studies, v.3, p.287-301, 2020 .

GEREFFI, G.; HUMPHREY, J.; STURGEON, T. The governance of global value chains. Review of International Politic Economy, v.12, n.1, p.78-104, 2005.

HUMPHREY, J.; SCHMITZ, H. The governance of global value chains. IDS Bulletin, v.32, n.3, 2001.

McKINSEY. Building supply chain resilience. 2020. Disponivel em: <http://www. mckinsey.com/business-functions/operations/our-insights/building-supply-chain-resilience? cid=eml-web>.

PONOMAROV, S.; HOLCOMB, M. Understanding the concept of supply chain resilience. International Journal of Logistic Management, v.20, p.124-43, 2009.

RAMAMURTI, R.; SINGH, J. Emerging multinationals in emerging countries. Cambridge - UK: Cambridge University Press, 2008.

UNIDO. Industrial Development Report: industrializing in the digital age. Geneva, 2020. 228p.

WIPO. Global Innovation Index: Covid-19 Pandemic's Expected Impact on Innovation. Geneva, 2020. 448p.

WIR. World Investment Report: Global Value Chains: Investment and Trade for Development. Geneva: UNCTAD, 2013. 264p.

WIR. International Production Beyond the Pandemic. Geneva: UNCTAD, 2020. 268p.

RESUMO - A fragmentação internacional dos sistemas de produção, que configura Cadeias Globais de Valor (CGV), é orquestrada por empresas multinacionais com suporte das tecnologias digitais. Nas últimas décadas, riscos e vulnerabilidades decorrentes de eventos imprevistos contestaram os fundamentos e colocaram em xeque a expansão e o desempenho das CGV. Por essa razão, as suas bases de operação já estavam sendo revistas e modificadas no sentido de criar resiliência. Não obstante, a dinâmica das CGV foi fortemente impactada pela pandemia do Covid-19. Com as CGV paralisadas, houve reações de governos nacionais e de empresas, tanto multinacionais quanto locais, para remediar problemas emergenciais. Tanto a paralização quanto as reações vão ter consequências para a reconfiguração das CGV no futuro. Neste artigo buscamos responder às questões: como evoluíram as GVC no pré-Covid? como empresas e governos estão reagindo? quais serão os fatores determinantes de mudanças? para então esboçar cenários de como serão reconfiguradas as CGV e o sistema internacional de produção. O Brasil, que ocupa uma posição particular nesse contexto, será sempre destaque nessa análise.

PALAVRAS-CHAVE: Cadeias Globais de Valor, Cadeias Globais de Fornecimento, Empresas multinacionais, Pandemia, Brasil.

ABSTRACT - The international fragmentation of production systems, which shapes the Global Value Chains, is orchestrated by multinational enterprises with the support of 
digital technologies. In the last decade, risks and vulnerabilities arising from unforeseen events challenged the GVCs' basic assumptions and jeopardized both their expansion and performance. For that reason, the GVCs' operational patterns were already being revised and modified to increase resilience. Notwithstanding, the Covid-19 pandemic had a tremendous impact. With the disruption of the GVCs, both governments and enterprises, whether multinational or local, reacted to mitigate the emergencies that arose. This disruption, as well as the reactions, will have consequences in the reconfiguration of the GVCs in the future. In this article, we seek to answer the following questions: How did the GVCs evolve in the pre-pandemic period? How are governments and enterprises reacting? Which will be the determinants for change? We will then outline scenarios for both the GVCs' reconfiguration and the dynamics of the new international production systems. Brazil has a specific role in those systems, which is highlighted in the analysis.

KEXWORDS: Global value chains, Global supply chains, Multinational enterprises, Pandemic, Brazil.

Afonso Fleury é professor titular Senior do Departamento de Engenharia de Produção da Escola Politécnica da USP. @ - afonsofleury@usp.br /

https://orcid.org/0000-0002-4511-6416.

Maria Tereza Fleury é professora e ex-diretora da Escola de Administração de São Paulo da Fundação Getúlio Vargas e ex-diretora da Faculdade de Economia e Administração da USP. @-mtereza.fleury@fgv.br / https://orcid.org/0000-0002-1570-5164.

Recebido em 21.9.2020 e aceito em $1^{\circ} .10 .2020$.

I Escola Politécnica, Universidade de São Paulo, São Paulo, Brasil.

II Escola de Administração, Fundação Getulio Vargas, São Paulo, Brasil. 
